\title{
Prepared to die: A reflection on responding appropriately to complex questions
}

\section{Stewart Kendall}

Stewart Kendall is a social worker currently working in the oncology area at Christchurch Hospital.

\section{Abstract}

This article is a reflective journey of my own 'in-the-moment' response to a client's question about how to appropriately respond to a terminal diagnosis. A brief summary is provided of the way I responded to this situation, followed by an exploration of other ways that I may have been able to respond that could have been more appropriate to the client's needs. My reflection proceeds to incorporate general ideas of how social workers can respond to challenging questions and situations.

\section{Introduction}

The young woman sat down opposite me, clearly aware of her children playing busily in the waiting room next door. We engaged in small talk about the weather and difficulties experienced finding a park. A stack of paperwork sat in front of me including pamphlets on how to deal with cancer, what to tell the children and information on income support. Early in the interaction it became evident that this was to be a highly emotionally charged situation. This young woman had recently been informed that despite treatment her cancer was continuing to progress. At this moment she was acutely and painfully aware that her life was about to end.

\section{Answering the unanticipated question}

I began by asking the client to describe in her own words what she understood was happening. As she went on to detail the situation, she proceeded to ask me the following question 'how do I accept the fact that I'm dying?' I must admit at this point I was slightly stunned and a touch of panic began to set in. My mind started churning over the appropriate reply to this simple but overwhelmingly complex question. White-knuckled, and avoiding direct eye contact, I began to talk about the value of openly communicating with her family about dying, focusing on those things that she was still able to do, and preparing by getting practical things in order. As I stumbled through this advice giving I was attempting to communicate that in doing these things she would be able to move closer to a general acceptance of what was happening. In retrospect I can see that I had jumped ahead, presuming that I needed to have the answer to this fundamentally unanswerable question. From a personal perspective the response I provided did not feel entirely sufficient. There was a nagging sense that perhaps I had missed the opportunity to give the client what she really needed at that time.

\section{Stepping back, why we might feel drawn to providing an answer}

The feeling of discomfort with my 'in-the-moment' response remained with me, and I took this to supervision to tease it out further. In reflecting on this situation in the supervision 
context I began to realise that I had overlooked something important in this encounter. Rather than providing a direct answer to this question, it would have been more helpful and empowering to assist the client in answering the question for herself. I began to see that in essence, she had been reaching out for help to make sense of what she was going through. Social work is at its core about empowering people, promoting self-determination and independence (Webb 2001). As indicated in 3.10 of the Aotearoa New Zealand Association of Social Workers' Code of Ethics, '...members work in ways that encourages and enables self-determination by clients' (Aotearoa New Zealand Association of Social Workers 2008). In the context of health social work, there is the potential to view one's self as the professional or knowledge holder which places the clinician in a position of power. As a rule, questions that involve notions of what a person should do, or the appropriate way to deal with a problem, have answers that are unique to each individual. Providing a generic answer can miss the core of what the person is reaching out for, and can be more about the professional meeting their own needs than the needs of the person they are working with. In a situation like this, it becomes vital to look to establish a power balance by placing the client in the position of the expert on themselves (Jackson and Samuels, 2010).

\section{Reflections on a different way of responding}

It is important to reiterate the emotionally charged nature of this type of interaction, and the level of focus and energy required to be able to navigate this effectively. In responding to these complex situations, the effective use of basic micro-counselling skills should not be underestimated (Miller, 2012). If used effectively, open questions and paraphrasing in particular can be invaluable in assisting the client to make sense of their experience and to find the answers appropriate for themselves (Miller, 2012). In terms of the variety of open questions that could be asked, the most apparent would be to ask a question using the client's own words. For example, in this situation I could have asked the client to explain what she meant by accepting that she was dying. This would have led to an understanding of specifically what she was struggling with in terms of facing the end of her life. If she was finding it difficult to answer this question, it could be followed up with a more targeted question, such as, 'if you were to accept the fact that you' re dying what would that look like?' This would have provided the client with the opportunity to talk about how she saw this process being more manageable for herself and the people around her. Other questions that may have been useful include: 'how would that change your approach to the time you have left?', 'how would that change the way you interact with your family?', and 'what do you think it would be like to die without having accepted it first?' As a practitioner it is valuable to develop a tool kit of different types of questions alongside other micro-counselling skills which complement being present and tuned in to the client's needs.

\section{Grief and loss, the process of meaning-making}

Clearly this was a situation with strong themes of grief and loss. It is important to acknowledge that grief is typically conceptualised in terms of the loss of another person. However, it is also a significant aspect of the experience of individuals who are facing the end of their own lives. These individuals will in the majority of cases grapple with a range of immense losses, including future milestones and life experiences, specific hopes and goals, being able to witness other people's milestones, independence, physical functioning and employment. The process of accepting and adjusting to these losses will be unique to each individual and will not necessarily follow a specific pattern. One perspective in the area of grief work focuses on facilitating the process of the individual making meaning of their loss (Gillies and Neimeyer, 2006; Goldsworthy, 2005). This approach seeks to challenge traditionally held 
Western views around the importance of finding ways to move on from a loss in a timely manner. Indeed, this meaning-making approach focuses on the individual finding ways to incorporate the loss into a new way of viewing the world (Gillies and Neimeyer, 2006). This client interaction was an opportunity to undertake grief work in assisting the client with making sense of her experience, and look at how she would continue to be and share her life with those around her with this new sense of loss. Significantly, this young woman did not have the luxury of a long period of time to reflect on her experience. It needed to be undertaken in a timely manner, alongside coping with the physical effects of the cancer on her body.

\section{Critical reflection as a tool for practitioner development}

This article has highlighted the value of reflection in enhancing social work practice. Part of this process includes periods of critical reflection on the content of our practice. The purpose of this aspect of reflection is to explore ways that our practice can be improved to be of the most possible benefit to our clients. In the midst of pressured situations it can be very difficult to respond in a calm and considered manner. As social workers we should be careful not to become overly focused on saying or doing the right thing. As summed up famously by Maya Angelou, 'I've learned that people will forget what you said, people will forget what you did, but people will never forget how you made them feel' (Kelly, 2003, p. 263). Through experience practitioners learn to use themselves and their own unique approach to engage with and assist the people they work alongside. Reflection plays a key role in this ongoing development process.

\section{Acknowledging the privilege of the work}

It is a privilege to have the opportunity to work alongside people during the most difficult moments of their lives. In assisting a person to make sense of and face their own death it is important to recognise that this process can be extremely difficult and painful. The appropriate social work response to such a seemingly insurmountable situation does not need to vary greatly from our approaches to more clearly manageable life challenges. Reflecting on this experience has revealed the importance of remaining as calm as possible in the pressure of the moment, tuning into what the individual needs, and drawing on one's toolkit of micro-counselling skills. In essence, rather than providing the answers ourselves, the key is to assist and empower our clients to find these for themselves.

\section{References}

Aotearoa New Zealand Association of Social Workers. (2008). The Code of Ethics of the Aotearoa New Zealand Association of Social Workers. Christchurch: Aotearoa New Zealand Association of Social Workers.

Gillies, J., \& Neimeyer, R. (2006). Loss, grief, and the search for significance: Toward a model of meaning reconstruction in bereavement. Journal of Constructivist Psychology, 19(1), 31-65.

Goldsworthy, K. (2005). Grief and loss theory in social work practice: All changes involve loss, just as all losses require change. Australian Social Work, 58(2), 167-178.

Jackson, K., \& Samuels, G. (2010). Multiracial competence in Social Work: recommendations for culturally attuned work with multiracial people. British Journal of Social Work, 56(1), 235-245.

Kelly, B. (2003). Worth repeating: More than 5,000 classic and contemporary quotes. Michigan: Kregel Publications.

Miller, L. (2012). Counselling skills for social work. London: Sage.

Webb, S. (2001). Some considerations on the validity of evidence-based practice in social work. British Journal of Social Work, 31(1), 57-79. 